\title{
ŽIŽEK E A VIOLÊNCIA DA LINGUAGEM - O CASO CHARLIE HEBDO COMO ADORMECIMENTO DO ESPAÇO SIMBÓLICO DOS SUJEITOS
}

\author{
[Žıžek And The Violence Of The Langugage - The Case of Charlie Hebdo As \\ SleEp Of The Simbolic Space of Individuals]
}

Wellington Amâncio da Silva *

Feliciano José Borralho de Mira **

\begin{abstract}
Resumo: Neste paper analisamos o conceito de violência subjetiva e violência objetiva (violência "simbólica" da linguagem) a parti de Žižek (2014), tendo com contexto o caso Chalie Hebdo aqui brevemente investigado a partir de suas charges como instrumento de racionalidade dos instintos. Tal foi desenvolvida por meio dos conceitos de violência aqui apresentados. Como paradigma dessa racionalidade, buscamos inferir o animal político de Aristóteles (1998) em vista da sua similaridade nas representações do homem em Hobbes (2003), a partir dos acontecimentos acima especificados, não tendo a pretensão de fazê-lo na tradição hermenêutica para cada um dois autores - embora o façamos em Žižek (2010, 2014). Pretendemos, por fim, compreender de que modo a violência pode ser exercida através da sexualidade e da política, instâncias, segundo Foucault, (2002), muito policiadas.

Palavras-chave: Violência das Linguagens; Slavoj Žižek, Chalie Hebdo.
\end{abstract}

ABSTRACT: In this paper we analyze the concept of subjective violence and objective violence ("symbolic" violence of language) from Žižek (2014) and with the context Chalie Hebdo case here briefly investigated from his cartoons as rationality instrument of instincts. This was developed through the concepts of violence presented here. As a paradigm of this rationality, we seek to infer the political animal of Aristotle (1998) in view of its similarity in the representations of man in Hobbes (2003), from the events specified above, having the intention to do so in the hermeneutical tradition for each one two authors although we do in Žižek (2010, 2014). We intend to finally understand how violence can be exercised through sexuality and politics, instances, according to Foucault (2002), very policed.

Keywords: Violence of Languages; Slavoj Žižek, Chalie Hebdo.

* Bolsista de Mestrado (CNPQ). Mestrando em Ecologia Humana e Gestão Socioambiental - UNEB/PPGEcoH. Especialista em Ensino de Filosofia. É vinculado ao grupo de pesquisa "Memória, Identidade, Territorialidade, Educação do/no Campo e Espaços de Sociabilidade" - UNEB e Grupo de Pesquisa "Ecologia Humana" UNEB/CNPq.m@ilto:welliamancio@hotmail.com

** Doutor em Socio-économie du Développement pela EHESS - École des Hautes Études en Sciences Sociales de Paris; Doutor em Sociologia Económica e das Organizações pelo ISEG-Instituto Superior de Economia e Gestão da Universidade Técnica de Lisboa. PósDoutorado em Estudos Culturais Comparados no Centro de Estudos Sociais da UniversidadedeCoimbra.m@ilto:felicianomira@hotmail.com 
[...] no sentido da paz, no seu próprio país, e da ajuda mútua contra os inimigos estrangeiros. Hobbes, 2003, p. 148.

\section{INTRODUÇ̃̃o}

Qlavoj Žižek (1949 -) é um filósofo esloveno marxista e lacaniano, e crítico cultural, pesquisador sênior do Instituto de Sociologia e Filosofia da Universidade de Lubliana, na Eslovénia, professor da European Graduate School, diretor internacional do Instituto de Humanidades da Universidade de Birkbeck entre outros. Ele escreve muito sobre teoria política, estudos culturais, psicanálise, teologia e teoria do cinema, às vezes de uma perspectiva polemista talvez necessária para os tempos atuais. Sobre uma das suas polêmicas investigamos os conceitos de violência subjetiva e violência objetiva (violência "simbólica" da linguagem), no intuito de compreender os últimos acontecimentos relacionados à revista semanal satírica denominada Chalie Hebdo e demonstrar introdutoriamente que tais fenômenos de violência corroboram para o adormecimento do espaço simbólico dos sujeitos - dimensão constituída por subjetivação e instância de controle social, isto é, de autopoliciamento, de negação ou aceitação de realidades, de respostas estruturadas ou em cadeia, sublimação, esquivamento cognitiva diante dos acontecimentos.

Diante do exposto, há quem afirme que a violência na contemporaneidade tem um caráter polissêmico e, por vezes, não localizado - seu lócus, portanto, não corresponde a sua matriz e seu sentido, do mesmo modo, não deixa saber seus objetivos. Em Filosofia, pois, reconhecer é tarefa complexa, mas, nem por isso uma motivação para sua suspensão ou encará-la com uma aporia. Portanto, suspeita-se que a violência contemporânea se mostra, até onde pode ser vista, isto é, em sua parcela diminuta de visibilidade, em caráter demasiadamente complexo. A dimensão maior desta violência, em sua configuração velada e ao mesmo tempo intrusiva, diz-se, é silenciosa e invisível - aí reside o fundamento da sua ferocidade.

Em vista da sua "invisibilidade" estratégica, e por isso, violenta em si mesma, Žižek (2014) contribuiu expressivamente ao 
seu estudo ao analisá-la em sua dimensão trina, a saber, a violência subjetiva, a violência "simbólica" da linguagem, ou violência objetiva e a violência "sistêmica"1 (ŽIŽEK, 2014, p.17). Visando entender alguns aspectos do caso Charlie Hebdo, aqui proposto, nos deteremos nas duas primeiras em leituras comparadas. Antes, porém, é preciso esclarecê-las naquilo que significam a partir do pensamento de Žižek.

Um primeiro encontro acerca do que Žižek (2014) afirma sobre violência subjetiva e violência objetiva pode confundir o leitor quando a sua familiaridade aos conceitos tradicionais de subjetivo e objetivo. Para o autor, a violência subjetiva é mais aquela que é absorvida cotidianamente pelas pessoas; aquela que, para diversos fins e visando despertar determinadas respostas, é apresentada de "modo didático" e de fácil apreensão, configurada por representações vigentemente convencionalizada. Subjetiva porque assimilada, ocorre mais ou menos segundo o conceito de subjetivação foucaultiano (2006), isto é, do sujeito como uma forma de constituição do ser; da subjetivação como práticas de constituição do sujeito - constituição essa que ao ser instituída no sujeito, como uma forma de ser, de estar, pensar e agir, têm-se um sujeito objetivado. Deste modo, subjetivação e objetivação dialogam ${ }^{2}$.

A violência subjetiva é visível, de fácil leitura, diáfana ${ }^{3}$. É desencadeada por agentes identificáveis (sejam eles mocinhos ou bandidos) - e é nisso que se constitui o seu maior fator de subjetivação: ver as autorias dos grupos da violência para compreender suas motivações num jogo geralmente, e porque não, necessariamente dicotômico em face de alteridades não aceitável e das similitudes sociais, culturais, econômicas e políticas que precisam ser preservadas no Ocidente, e ainda, devem ser justificadas pela violência como resposta aos sujeitos violentos não legitimados para tal. Assim, a violência subjetiva é aquela que é "vista como uma perturbação do 'normal', do estado pacífico das coisas" (ŽIŽEK, 2014, p. 2).

A violência objetiva, mesmo diante dos seus amplos modos de vitimizar, é aquela que se quer esconder, porém, segundo Žižek (2014) pode ser mirada obliquamente (idem, p. 19). Entender tal 
violência, em sua complexidade, pode ser a chave para compreender suas forças estorvativas da liberdade e da democracia que ela mesma insiste em defender como os dois baluartes da civilização.

\title{
O Animal político de Aristóteles e de HobBes
}

Pedimos desculpas pela imagem não ortodoxa de leitura filosófica, mas se observássemos a leitura moderna da Natureza a partir das lentes do seu desencantamento 4 , poderíamos "entrever" Hobbes (2003) lendo Aristóteles (1998) e assim tirando certas

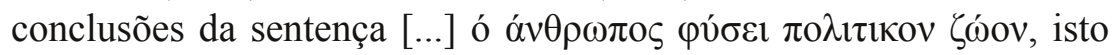
é, o homem é naturalmente um animal político ${ }^{5}$. De acordo com o sentido menos eufêmico do "animal político", daquilo que Aristóteles (1998, p. 52) deixou nas entrelinhas, Hobbes certamente foi tirar do sujeito o Homo homini lúpus, isto é, "homem lobo do homem", acabando com o encanto da "convivência pacífica" a não ser condicionada ao Estado como poder orientador das relações em sociedade em face dos ânimos dessa liberdade-animalidade inerente ao o homem (2013, p. 147). Visto que:

\begin{abstract}
[...] graças a esta autoridade que lhe é dada por cada individuo na república, é-lhe conferido o uso de tamanho poder e força que o terror assim inspirado o torna capaz de conformar as vontades de todos eles, no sentido da paz no seu próprio país, e da ajuda mútua contra os inimigos estrangeiros. (HOBBES, 2003, p.147148).
\end{abstract}

As performances do animal são visivelmente peculiares contra "inimigos estrangeiros", ou - atualizando a sentença para as demandas atuais -, o animal é sempre arisco e impiedoso contra o não familiar, uma inimizade suscitada no estranhamento e na desconfiança em face da manutenção de territórios determinados. Portanto o Estado pode ser entendido como uma organização interessada de animais ( $\zeta \omega ́ o v)$ que ao mesmo tempo pelo seu $\zeta \omega ́ o v$ $\lambda o ́ \gamma o v$ ć $\chi o v^{6}$, isto é, sua "faculdade da linguagem" (ARISTÓTELES, 1998, a 9-10, p. 55), articula essa ordenação de poder contra o Outro-animal, contra o estranho-inimigo que ameace conquistar seu território e suas territorialidades subjetivas de interesses. Nesse 
sentido, a sentença [...] o homem é naturalmente um animal político (ARISTÓTELES, 1998, p. 52), à luz dos últimos acontecimentos - e no contexto de como esta sentença configurou o pensamento ocidental -, podemos pensá-la como conceituação da condição primária do homem ao articular sua animalidade através da política? Que é o único que detém a faculdade de transpor o irracional do animal em racionalidade na linguagem? Que algumas vezes essa "bipolaridade" se manifesta consecutivamente e/ou ao mesmo tempo? Um homem só não é político, mas apenas a partir do encontro com o outro nos limites de suas diferenças, do consenso e da linha tênue da tolerância. Destarte, nos parece que a política é o campo limítrofe onde o homem escolhe ser humano ou deixar-se ao animal. E no entendimento convencionalizado acerca do Bem e do Mal, o pathos da solidariedade universal (ŽIŽEK, 2015) se efetiva como uma escolha política, onde a convicção lógica da racionalização do que é o Bem e do que é o Mal corresponde apenas

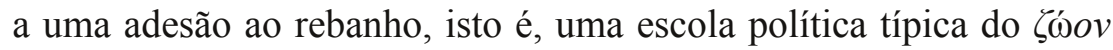
"aristotélico", processada no discurso, na linguagem que obscurece dos instintos motivadores de tal escolha. Talvez o que Aristóteles propôs com o homem-animal-político seja a ideia de um equilíbrio entre instintividade e racionalidade no âmbito da pólis. Ante o Outro-estranho - aquele outro não iniciado nos mistérios da pólis não haveria equilíbrio; a convivência "pacífica" ou a tolerância com os do "rebanho" é o interstício onde o animal descansa. Do que foi dito, a política seria o limite entre o homem e o animal, lugar de onde eles se entreolham (Figura 1). Se tomássemos o animal como uma referência contrária, a linguagem nos faria perceber, da naturalidade dessa condição de animal político que, sendo homem, queremos fugir do animal em busca de alguma humanidade, quando o logro não é apenas para si? A humanidade que temos construído é, ainda que por vezes não se reconheça, tudo aquilo que a referencial animal nos inspira a não ser? A humanidade é a negação consciente do animal que somos - já o animal não saberá negar qualquer humanidade: ele a recebe "à sua maneira". De todo modo, se a "violência pertence à linguagem enquanto tal" (ŽIŽEK, 2014, p. 17), sobretudo quando se lança à política do animal, isto é, quando a pulsão escondida almeja o acomodo que acalenta os instintos, como 
conceituar a paz enquanto ideia de humanidade dentro desse turbilhão feroz de signos em sua polissêmica? A paz é mais bem promovida pela simulação da ausência?

FIGURA 1

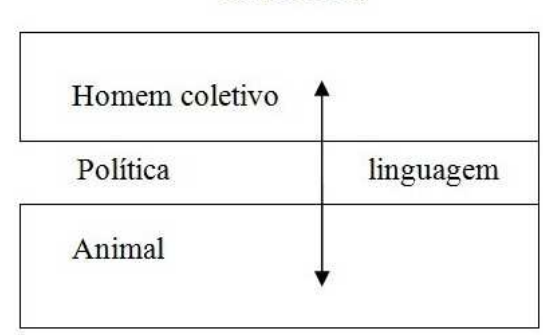

Fonte: dos autores

Da Figura 1, é possível postular acerca do discurso hobbesiano sobre uma política como a própria representação do Estado, ao tentar organizar e separar o animal do homem, o instinto do racional e o caos da ordem - e é pela adoção consciente das regras do Estado - uma alienação necessária do poder - que o homem descansa da suspeita para confiar em seu semelhante que agora é $\mathrm{um}$ igual determinado pelos almeje de pacificidade descodificados na linguagem.

Se assim for, a política é a instância que simula algum tipo de separação e ordenação entre a humanidade e a animalidade; mas, a luta que se trava nesse processo é velada para as multidões; o que se torna público é um aparente; sua normalidade é a repetição constante do inequívoco, daquilo que perfaz um caminho óbvio, mas atento aos surtos de monotonia, instala-se por vezes alguma eventualidade que, por assim dizer, tem como sentido perfazer a lembrança do inequívoco como o possível para a paz. Por outro lado, se Aristóteles estiver certo e permitir esta "hermenêutica", ainda que por vezes se negue, a linguagem (como política), consegue, dentro dos seus limites de significação e equivocação, interconectá-las, humanidade e a animalidade, entre si. Portanto, a linguagem seria, grosso modo, um instrumento para a racionalidade dos instintos, e obviamente, conditio sine qua non do seu controle ${ }^{7}$. Os resultados disso, por exemplo, daquilo que se comunica numa "charge" de Hebdo, 
desperta naqueles que se opõem à "charge", a instintivação da razão através do cano de fuzil ${ }^{8}$ - e isso, por uma questão de aporia entre ininteligibilidade ante a compreensão de conceitos dessemelhantes. Em última instância, é o homem, em seu estado animal, que "compreende" aquilo que não deseja numa instância política e transforma em resposta violência a partir de uma instância que anula qualquer diálogo político, dentro do campo do possível da linguagem: o fuzil e/ou a "charge".

\section{A LINGUAGEM DA VIOLÊNCIA E A VIOLÊNCIA DA LINGUAGEM}

Antes é preciso conceituar, ao menos, racionalidade e racionalização, antes de tentar articular linguagem e violência. Para Morin (2003) a racionalidade é o estabelecimento de adequação entre uma coerência lógica (descritiva, explicativa) e uma realidade empírica (idem, 2003, p. 157). Assim, o animal político se realiza como homem com o outro, isto é, através da racionalidade daquilo que antes só podia ser sentido para consigo mesmo. Por conseguinte, entendamos por a subjetividade a dimensão primeiro interior, lugar onde as pulsões são mais ou menos coordenadas, orientadas, liberadas ou negadas pela razão e, por objetivação são apresentadas como fatos como realidade empírica. Sobre essa questão, a racionalização, isto é, "a construção de uma visão coerente, totalizante do universos a partir de dados parciais, de uma visão parcial" (idem, 2003, p. 157), apenas dissimula o caráter animal e "privado" desses fenômenos.

A exteriorização dos sentidos transporia a intraduzível pulsão do "animal sem linguagem" primeiro na racionalização dessas pulsões e depois na explicação lógica destas como uma espécie de "discurso freudiano". O que a linguagem diz, diz sempre nos limites desse amálgama, entre domesticação da pulsão, (o movimento vital) como expressão estática e por isso mesmo conformada. Esse polimento institui a legitimidade da sua expressão como discurso do sexo, discurso das necessidades fisiológicas, discurso da forme, discurso da morte e posteriormente como discurso deliberativo da violência. No caso da figura 2 e 3, temos a sexualidade como 
pulsão e a política como linguagem em constante tensão, tendo daí uma anomia com finalidades hilárias, pela "simples" junção entre fórmulas em visível aporia. Um feito maliciosamente criativo ${ }^{9}$ ao se divertir com a dessacralização dos conceitos ocidentais de sexualidade em face às sacralidades orientais da sexualidade.

Figura 2, intitulada "Mahomet: Une etoile est née Charlie Hebdo", by Charlie Hebdo
Figura 3 intitulada "Le film qui embrase le monde musulman", by Charlie Hebdo

Nota: As imagens referidas possuem copyright, e a revista não recebeu autorização para uso público, pelo que, cumprindo seu código de boas práticas, recomenda que o leitor faça uma busca simples na web com os nomes das imagens que será imediatamente suprido.

Por incrível que pareça, lida-se aí com política. Para Foucault (2002), "as regiões onde a grade é mais cerrada, onde os buracos negros se multiplicam, são as regiões da sexualidade e as da política" (Idem, p. 9). Ambas são poder desperto, num entrelaçamento com o prazer, como duas instâncias de gozo policiadas, a do homem político com a do animal sexual. Sexualidade e política suscitam fenômenos criativos, mesmo que seu conteúdo seja desnecessário.

Na figura 2, temos o titulo, "nasce uma estrela" para uma composição inusitada. A correlação inexiste entre estrela e ânus, portanto, desperta facilmente a hilaridade num público preparado, em seu espaço simbólico, para responder a tal "estímulo". Se estrela conota o alto, o astro, a arte, o desejado, o brilhantismo, por sua vez, o ânus denota o interstício humano de descarte das excrescências, ou, de uma perspectiva "anti-ideológica" contra mulçumanos, o "local da impraticabilidade sexual". Também na Figura 3, sob o título de "le film qui embrasé le monde musulman" isto é, "o filme que inflamou o mundo muçulmano" ${ }^{10}$, há uma representação de androginia onde o personagem - um mulçumano tradicional num corpo feminino em pose tipicamente sensual -, pergunta: "et mes fesses? tu les aimes, me fesses?", ou seja, "e minha bunda? Você gosta da minha bunda?". Numa posição de total "passividade diante de", ao mesmo tempo em que sugestiona e banaliza de modo preconceituoso a homossexualidade (Figura 2), atribui-se significados extremamente "mundanos" ao profeta beduíno do povo muçulmano, que podem ser facilmente vistos por esse povo como 
expressões de um terrorismo linguístico para além dos valores basilares da Liberdade de Expressão longamente conquistados no Ocidente - até onde esse povo pode apreender os sentidos ocidentais de liberdade.

Nos perguntamos se o que provoca a gargalhada é a impossibilidade de interpretação pela ausência de correlação entre os signos numa composição ou a passividade radical de alguém tido como representação de uma parcela de crueldade contemporânea. É possível que imagens opostas se sustentem através do riso, quando o pathos convicção coloca em jogo "democracia" e "teocracia" - duas linguagens abstratas? Ou ainda, como a associação entre universos impossíveis despertaria uma gargalhada ${ }^{11}$ que se prolonga cada vez mais através das muitas leituras de um fenômeno. Estas são questões em epoché, postas para depois, em face das ausências, impossibilidade e negação no campo da linguagem.

De uma perspectiva dicotômica, temos assim ou "la liberté d'expression est un droit fondamental" como expressão de violência subjetiva da sexualidade ou temos a resposta terrorista como violência subjetiva pela anomia como resposta ao que o outro ofendido não pode, não consegue e nem quer "compreender". Se naturalmente o homem é um animal político", o "caos exterior à pólis" (porque a ordem aristotélica é condicionada à pólis) adentra por suas portas como a ausência de uma linguagem inteligível, impossibilidade de uma hermenêutica do consenso e negação de representações agradativas dentro de uma linguagem amplamente divulgada, acriticamente adotada e convencidamente compreendida. Portanto, como foi dito, dá-se mais importância em si para "la liberté d'expression est un droit fondamental" do que ao seu conteúdo. Por vezes, há de se perceber que o problema não é o da censurar inerente à violência subjetiva que visa tudo dizer, mas da censura inerente à violência objetiva como um conteúdo "ininteligível" que circula cotidianamente. O que está por trás de todos esses fatos?

O quadrado e a letra: a forma racional da charge como instrumento organizador dos instintos de violência em uma abordagem oblíqua, portanto, metafórica 
Assim, como Žižek, é necessário investigar os fatos, porém, mantendo-se "[...] a uma distância respeitosa em relação às vítimas" (2014, p. 19), visando o afastamento possível e condicional da vida dos autores de Chalie Hebdo para se aproximar apenas da sua obra polêmica. De todo modo, "o difícil é justamente combinar o calor do momento com o ato de pensar. Refletir quando o rescaldo dos eventos esfriar não gera uma verdade mais balanceada, ela na verdade normaliza a situação de forma a nos permitir evitar as verdades mais afiadas" (ŽIŽEK, 2015).

Tendo, portanto, a charge como instrumento de comunicação de alguma coisa, podemos afirmar que a linguagem tem a capacidade de construir uma aparência de razão sobre o que "antes" eram os instintos. Ainda, a linguagem tem acesso aos instintos pela via das representações inteligíveis ${ }^{13}$, pela via da hermenêutica desses instintos, atribuindo assim, como um eufemismo, um aspecto racional ao que antes era caos através dos seus discursos. Portanto, a charge, uma arte vinculada à imprensa, símbolo da liberdade de expressão, fruto do iluminismo, é vista como a manifestação da própria razão; o seu formato resolve a priori o problema da antinomia, isto é, o papel impresso, os tipos, o layout, a forma quadrada, títulos, textos, parágrafos, certa lógica argumentativa contida nas sentenças, resolvem suficientemente nossas reivindicações de ordem lógica; sua similitude como "produto genérico" de tudo o que é organizado, civilizado, intelectivo determinaria aceitabilidades. Enfim, sua configuração convencionalizada de jornal pode impor-se, aos espíritos adormecimentos pela banalização da violência subjetiva, como uma ratio ou um registro lógico, antes de qualquer pré-julgamento perante os irracionalismos do seu conteúdo ${ }^{14}$. O adormecimento pela banalização da violência subjetiva, isto é, a insensibilidade como resposta à violência absurda ou apatia provocada a partir de uma interpretação dos fatos é a reação típica da maioria dos sujeitos expostos: no caos de tudo aquilo que é desagradável e, sobretudo, imprevisível, a construção do senso de obviedade representaria uma instantânea aceitação dos dispositivos de similitude linguagem, como a charge, o jornal, a notícia, televisiva, os slogans, as sentenças 
breves, mas "violentamente incisivas". Consequentemente, se quanto maior for à exposição banalizante à violência, tanto maior a busca será em esquivar-se cognitivamente dos "fatos" e da adoção de linguagens que afastem, contradigam, escarneçam tais fatos.

Sobre adormecimento do espírito como o que pode ou não circular no espaço simbólico do sujeito, Žižek (2014, p.18) nos apresenta um caso, quase sem resposta efetiva do público leitor, divulgado na revista Times de 05 de junho de 2006, onde "quatro milhões de cidadãos teriam sido mortos na República Democrática do Congo devido à violência política das últimas décadas". A ausência de "efeito mais forte no espaço simbólico" dos leitores da Times, poder denunciar uma transformação profunda e, porque não, homogênea na "educação cotidiana" como mudança de comportamento (behaviorista) dos sujeitos em geral. Em outras palavras, o que não desperta identificação e não suscita cossemelhança é insensibilizado no espaço simbólico da coletividade. Já um caso contrário a este é do noticiado no Les Echos, um famoso jornal francês, que "após quinta-feira 8 de janeiro, o dia do ataque [ao Chalie Hebdo por terrorista, os jornais daquele] saltaram de vendas global de 600.000 cópias por dia normal de 1 milhão, de acordo com o Sindicato da Imprensa Cotidiana Nacional”. (LES ECHOS, 2015).

\section{CONSIDERAÇÕES FINAIS?}

Dentro de uma pirâmide cartesiana de hierarquias animais, o homem se destaca por sua ferocidade. A política é uma ferramenta de abstração e humanidade que sublima uma agressividade animal; nela, a ação humana mais expressiva de sublimação de animalidades. Violência subjetiva como proposta política de controle social constante e violência objetiva como o lócus da política desse animal. Por causa disso, encarar tal desafio interpretativo, diante dos significados postos para a expressão aristotélica, além de ser, aparentemente um disparate anti à Tradição seja talvez um retorno desesperado, porém desafiador para tentar responder o que é o homem hoje a partir do que ele pensa ser desde os antigos. O caso 
Hobbesiano do homem como lobo do homem e animal incorrigível em seu egoísmo nos parece uma interpretação adequada à expressão grega do "animal político". O caso Chalie Hebdo nos desperta a suspeita em face do discurso angustiado da liberdade de expressão que apregoar sem se debruçar sobre o dito. Sobre como os tipos de violência típicas do Ocidente desentocam a violência do Outroestranho, e apesar da aparente "outridade" desses discursos de morte,

116 ambos são se imitam: um e outro ferindo o que o outro consagra como ideais. Sabemos que tese a e antitese correspondem sempre ao desejo de uma resposta equalizada entre aqueles que, dentro de um jogo de linguagem, de regras postas, de acordos estabelecidos, buscam se conhecerem e, nisso, conhecer é conditio sine qua non de sintese. Com efeito, a síntese que deseja demonstrar-nos que uma dialética, no sentido de diálogo, na contemporaneidade, parece estar se afastando de nós.

\section{REFERÊNCIAS}

ARISTÓTEleS. Política. Tradução de Antonio Campelo Amaral e Carlos de Carvalho Gomes. Lisboa: Editora Vega, 1998.

DARWIN, Charles R. A origem das espécies e a seleção natural. Tradução de Eduardo Nunes Fonseca. São José: Gráfica 66, 2003

FREUD, Sigmund. O Mal-Estar na Civilização. Tradução Paulo César de Souza. São Paulo: Companhia das Letras, 2010.

FOUCAULT, Michel. A ordem do discurso. 8. ed. Tradução de Laura Fraga de Almeida Sampaio. São Paulo: Loyola, 2002.

. Ditos e Escritos IV. 3. ed. Tradução de Vera Lúcia Avellar Ribeiro. São Paulo: Editora Forense Universitária, 2006.

HOBBES, Thomas. O Leviatã ou Matéria, Forma e Poder de um Estado Eclesiástico e Civil. Tradução de João Paulo Monteiro e Maria Nizza da Silva. São Paulo: Martins Fontes, 2003

KANT, Emmanuel. Crítica da Razão Pura. Tradução de Manuela Pinto dos Santos. 7. ed. Lisboa: Calouste Gulbenkian, 2010.

LES ECHOS. La presse française portée par l'effet "Charlie Hebdo". 16 de janeiro de 2015.

LE MONDE. Film anti-islam: 150 manifestants arrêtés près de 
l'ambassade américaine à Paris. Edição de 15.09.2012. < http://www.lemonde.fr/societe/article/2012/09/15/film-antiislam-150-manifestants-arretes-pres-de-1-ambassade-americainea-paris_1760975_3224.html >Acesso em 11 de fevereiro de 2015

MARX, Karl; ENGLES, Friedrich. Manifesto do Partido Comunista. 13. ed. Tradução de Marcos Aurélio Noqueira e Leandro Kondé. Petrópolis: Vozes, 2005.

MORIN, Edgar. Ciência com consciência. Tradução de Maria D.

Alexandre e Maria Alice Sampaio Dória. 7. ed. Rio de Janeiro. Bertrand, 2003.

WEBER, M. Weber, Max. A ética protestante e o "espírito" do capitalismo. Tradução José Marcos Mariani de Macedo. São Paulo: Companhia das Letras, 2004.

ŽIŽEK, Slavoj. Violência. Tradução de Miguel Serras Pereira. São Paulo: Boitempo, 2014.

. Visão em Paralaxe. Tradução de Maria Beatriz de Medina, São

Paulo: Biotempo, 2008.

. Slavoj Žižek on the Charlie Hebdo massacre: Are the worst really full of passionate intensity? 10 de janeiro de 2015. http://www.newstatesman.com/world-affairs/2015/01/slavoj-iek-charlie-hebdo-massacre-are-worst-really-full-passionateintensity. Acesso em 07 de fevereiro de 2015.

\section{Notas}

1 A violência sistêmica é a violência justificada e necessária por certos discursos e como efeitos de certas causas; se constitui dentro da sociedade contemporânea naquilo que está estruturalmente é (violenta em si mesma). A violência sistêmica é a expressão essencial dos sistemas econômico e político.

2 Sobre a concepção de sujeito e objeto, conceitos que oriental as questões acima apresentadas, veja por exemplo, Žižek, 2008, p. 30.

3 Toda essa transparência dos sentidos da violência subjetiva por parte dos sujeitos é anteriormente ensinada nas escolas, pelas mídias, e outras instituições ideativas, sempre na perspectiva binária do justo e do injusto, do Bem e do Mal por meio da "imposição de um certo universo de sentido".

4 Kant, 2010; Weber, 2004; Darwin, 2003; Freud, 2010; Marx e Engels, 2005, para citar alguns exemplos concordantes.

5 ARISTÓTELES, 1998, A 2.3/I. 2, p. 52 


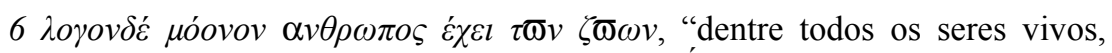
apenas o homem possui palavra". ARISTÓTELES, 1998, a 9-10, p. 55

$7 \mathrm{O}$ controle dos instintos é sempre um exercício que demanda violência. Entendamos violência num sentido de governo, num ato de domar, dominar, etc.

8 O fuzil que matou membros do Charlie Hebdo é o dispositivo cujo "discurso" monólogo - equidistância absoluta do discurso da linguagem -, se materializa como uma protuberância de um animal feroz, animal que visa à proximidade para o assassínio. Em contraste, o Rugir de um tigre não é um "discurso" que afasta, mas o desejo de proximidade que devora. No fuzil materializa-se esse desejo: o "discurso" do fuzil é a realização completa da materialidade do "discurso" que pela ausência total de abstração (visto seu espaço é preenchido de concretude violenta) impossibilita qualquer condição de linguagem e comunicação, isto é, possibilidades de tecer qualquer argumento para a neutralização ou adiamento da morte. A materialidade do "discurso" do fuzil é assim, porque é o próprio conteúdo da morte e do desejo de aniquilamento do outro no próprio "discurso"; este carrega em si o conteúdo da morte como um som que tem pressa de cessar pela violenta pulsão do ódio e da ausência plena de qualquer resquício de concórdia e de perdão que é, por assim dizer, um medo instintivo das "pausas da razão", isto é, de arrepender-se em face da indefesa do outro.

9 Comumente a expressão criatividade e criativo soam positivamente. Nos parece que não há ainda uma interpretação séria sobre ambas. Ainda nos parece que la liberté d'expression est un droit fondamental, mesmo que seu conteúdo não seja fundamental.

10 Após ser veicular na Internet o curta de 13 minutos intitulado Innocence of Muslims, produzido por Nakoula Basseley Nakoula, causou comoção entre os mulçumanos, desencadeando uma série de protestos em todo mundo. Veja Le monde, de 15 de setembro de 2012

$11 \mathrm{O}$ esvaziamento do sentido da gargalhada provocaria mais gargalhada? - a quem diga que para rir não basta um sentido. Assim como o gozo do sexo pelo sexo, o gozo da gargalhada é ecoado como aquilo que desfaz o que a política constituiu?

12 Aqui apresenta-se a mais razoavelmente aceitável interpretação para o termo aristotélico citado acima que poderia resolver teoricamente as contradições entre o homem e o animal no campo da política e da linguagem.

13 Por exemplo, no modo como os instintos são representados e, por conseguinte, relacionados a um tipo de racionalidade distinta da racionalidade ocidental. Figura 2 e 3.

14 O próprio irracionalismo representado pela mídia sensacionalista corrobora com a insensibilização das pessoas diante dos fatos, como um mecanismo psicológico de negação, sublimação ou "esquecimento". 